\title{
A JUSTIÇA RESTAURATIVA COMO PROPOSTA ALTERNATIVA AO PARADIGMA RETRIBUTIVO
} RESTORATIVE JUSTICE AS AN ALTERNATIVE TO THE COMPENSATION PARADIGM LA JUSTICIA RESTAURATIVA COMO PROPUESTA ALTERNATIVA AL PARADIGMA RETRIBUTIVO

Maria Coeli Nobre Silva ${ }^{1}$

Gustavo Raposo Pereira Feitosa²

Daniela Veloso Souza Passos³

1 Doutora em Direito pela Universidade de Fortaleza - UNIFOR; Mestre em Direito pela Universidade Federal da Paraíba, área de concentração em Direitos Humanos. Professora Adjunto IV do Centro de Ciências Jurídicas da Universidade Federal da Paraíba- UFPB; Juíza de Direito do Estado da Paraíba, aposentada Maria Coeli Nobre. Fortaleza-Ce, coelinobre@ yahoo.com.br.

2 Advogado, Doutor em Ciências Sociais pela Unicamp, Professor do Programa de Pós-Graduação em Direito Constitucional da Unifor. Coordenador do Mestrado Profissional em Direito e Gestão de Conflitos; Líder do Grupo de Pesquisa Justiça em Transformação - JET. Fortaleza-Ce, gfeitosa@terra.com.br.

3 Doutoranda em Direito na Universidade de Fortaleza; Mestre em Direito Constitucional pela Universidade de Fortaleza (2013); Professora da Universidade de Fortaleza, onde ministra as disciplinas de Direito Constitucional e Sociologia Geral e do Direito. Assessora do Núcleo de Pesquisa do Centro de Ciências Jurídicas e Coordenadora do Laboratório de Jurisprudência da Universidade de Fortaleza - Unifor, Fortaleza-Ce, danivspassos@hotmail.com. 
Resumo: O presente trabalho tem por objetivo fazer uma análise da Justiça Restaurativa como uma alternativa eficaz ao paradigma retributivo punitivo. A importância de tal tema reside no fato de que o arcabouço jurídico punitivo tradicional se apresenta em crise e, por seu caráter burocrático, impessoal e excludente, mostra-se incapaz de resolver os conflitos sociais e reabilitar o infrator. Utiliza-se do método dialético, mediante uma abordagem qualitativa e critério de pesquisa histórico bibliográfico, por meio do qual se fará um percurso metodológico com vistas à compreensão do processo de racionalização do Estado a partir do paradigma weberiano. Pretende-se, por fim, analisar as principais características da justiça restaurativa que fazem dessa nova proposta de resolução de conflitos uma alternativa eficaz ao sistema punitivo. Como resultado da pesquisa, verifica-se que, ao ampliar a visão da resolução do conflito para além do Estado, a Justiça restaurativa compromete-se com a inclusão e a justiça social, primando pelo interesse das pessoas envolvidas na comunidade, representando, portanto, uma importante mudança de paradigma no processo penal, com benefícios para o infrator e para a coletividade.

Palavras-chave: Direito Penal. Justiça Restaurativa. Justiça de Proximidade.

Abstract: This work analyzes restorative justice as an effective alternative to the punitive compensation paradigm. The importance of this subject lies in the fact that the punitive legal framework is presented as being in crisis, and due to its bureaucratic, impersonal and exclusive nature, it is unable to resolve social conflicts and rehabilitate the offender. The dialectical method is used, through a qualitative approach and historical-bibliographic research. Through this means, a methodological path is taken towards understanding the process of rationalization of the State, based on the Weberian paradigm. The final goal is to analyze the main features of restorative justice that make this new proposed form of conflict resolution an effective alternative to the punitive system. As a result of the research, it is seen that by expanding the vision of conflict resolution beyond the State, restorative justice is committed to inclusion 
and social justice, striving for the interests of those involved in the community, and as such, representing an important paradigm shift in criminal proceedings, with benefits for the offender and for society as a whole.

Keywords: Criminal Law. Restorative Justice. Justice Proximity.

Resumen: El presente trabajo tiene por objetivo hacer un análisis de la Justicia Restaurativa como una alternativa eficaz al paradigma retributivo punitivo. La importancia de este tema reside en el hecho de que el marco jurídico punitivo tradicional se muestra en crisis, y que por su carácter burocrático, impersonal y excluyente se muestra incapaz de solucionar los conflictos sociales y rehabilitar al infractor. Utiliza el método dialéctico, mediante un enfoque cualitativo y un criterio de investigación histórico bibliográfico, por medio del cual se trazará un trayecto metodológico con el propósito de comprender el proceso de racionalización del Estado a partir del paradigma weberiano. Por último, pretende analizar las principales características de la justicia restaurativa que hacen de esa nueva propuesta de resolución de conflictos una alternativa eficaz al sistema punitivo. Como resultado del estudio se verifica que al ampliar la visión de la resolución del conflicto más allá del Estado, la Justicia restaurativa se compromete con la inclusión y la justicia social, primando por el interés de las personas involucradas en la comunidad, representando de esta manera un importante cambio de paradigma en el proceso penal, con beneficios para el infractor y para la colectividad.

Palabras clave: Derecho Penal. Justicia Restaurativa. Justicia de Proximidad.

INTRODUÇÃO

á mais de três séculos que se presencia um arcabouço do sistema penal direcionado quase que exclusivamente a atender à pretensão punitiva do Estado. Partindo de uma lógico repressiva e de controle, 
centraliza-se a resolução do conflito na relação entre o Estado e o infrator, sem levar em consideração a perspectiva da vítima. Diante da crise por que tem passado referido paradigma, evidencia-se a necessidade de se repensar em um novo modelo de justiça que leve em consideração os interesses da vítima na resolução do litígio.

Diante desse problema, o presente trabalho tem por objetivo fazer uma análise dos principais elementos caracterizadores da Justiça Restaurativa que fazem dessa nova proposta de resolução de conflitos uma alternativa eficaz ao paradigma ${ }^{4}$ punitivo retributivo do Estado. Para tanto, far-se-á um estudo sobre o sistema punitivo a partir de uma perspectiva sociológica weberiana de racionalização do Estado e do Direito, para, por fim, analisar as principais características da justiça restaurativa que fazem dessa nova proposta de resolução de conflitos uma alternativa eficaz ao sistema punitivo.

A partir do seu estudo sobre o processo de racionalização do Estado moderno, Max Weber traz uma importante contribuição ao que se tornou conhecido como Sociologia do Conhecimento, construindo importantes categorias teóricas para a compreensão da legitimidade do Estado como detentor do poder de punir.

Com efeito, utilizando-se de uma abordagem interdisciplinar de caráter histórico bibliográfico, o presente trabalho abordará o processo de racionalização do Estado a fim de inserir o Direito Penal dentro de uma perspectiva da racionalidade moderna, que, devidamente preocupada com aspectos formais, deixa de lado aspectos humanísticos das partes envolvidas no conflito, mostrando-se incapaz de cumprir algumas das principais finalidades propaladas como essenciais a este sistema, tais como a ressocialização ou a punição eficaz.

Em um contexto de crise do atual paradigma do sistema de justiça pautado na formalidade e impessoalidade, a Justiça Restaurativa constitui um importante instrumento de resolução de conflitos. Ao buscar o tratamento do conflito por meio de formas exógenas e, em geral, externas ao Estado, o modelo de justiça restaurativa insere a vítima, ofensor e a própria comunidade como partes

4 Sem adentrar às rígidas discussões científicas sobre a exigência constitutiva de um paradigma, a linha de raciocínio desenvolvida adota o termo paradigma no sentido de parâmetro, modelo ou padrão a ser seguido. 
integrantes do processo restauratório em um meio consensual e dialógico que Ihes permite participar coletiva e ativamente da construção de soluções, bem como da "cura" dos traumas e das perdas causados pelo crime.

Não se pretende adotar uma postura "abolicionista" no sentido do abandono total das práticas tradicionais de resolução dos conflitos penais, mas sim apontar para a eficácia e importância da adoção de uma proposta alternativa que venha a permitir a solução de alguns conflitos de forma consensual, inserindo a vítima e o acusado no centro das discussões, possibilitando a superação da rigidez das fórmulas burocráticas do Estado contemporâneo e uma atuação mais eficaz sobre os conflitos nascidos das infrações penais.

\section{O PARADIGMA RETRIBUTIVO E A LÓGICA BUROCRÁTICA WEBERIANA}

O poder de punir consiste num dos elementos mais marcantes do Estado. As transformações que levam à definição dos contornos do Estado contemporâneo envolvem sempre uma discussão sobre a capacidade estatal de usar a força sobre os indivíduos. A contenção do uso direto da violência punitiva pelos cidadãos, a regulação da capacidade de punir do Estado e a limitação do uso da violência por agentes públicos expressam aspectos centrais do processo de construção dos estados liberais, das transformações acarretadas pelas lutas sociais desde o século XVIII e, em síntese, de um amplo percurso de racionalização estatal com pretensões "civilizatórias"5.

A pena é um elemento central deste Direito Penal moderno utilizada pelo Estado como um instrumento de repressão. A sua finalidade última é reprimir um ilícito por meio do "castigo", visto agora não apenas como um espetáculo coletivo da punição, mas como uma punição pensada de maneira mais imediata em seus efeitos sobre o indivíduo. Essa resposta ao ilícito passou gradativamente por uma ressignificação, constituindo-se em um meio no plano teórico, numa ferramenta para prevenir a reiteração dessas condutas, assim como ressocializar o ofensor.

$5 \quad$ Neste aspecto, merecem destaque os sentidos dado a este processo em: ELIAS, Norbert. O processo civilizador: Uma história dos costumes. Tradução de Rui Jungmann. Rio de Janeiro: Jorge Zahar, 1994 e FOUCAUT, Michel. Vigiar e Punir: Nascimento da prisão. Tradução de Raquel Ramalhete, Petrópolis: Vozes, 1999. 
É dentro desse contexto que se cria a pena privativa de liberdade como instrumento de controle social por parte do Estado, tornando-se o paradigma punitivo no atual sistema de justiça penal ${ }^{6}$

Max Weber, ao analisar a relação entre o Estado moderno e o capitalismo, dá uma importante contribuição para a compreensão da legitimidade do Estado como detentor do poder de punir. Na análise de Weber, o Estado é definido como "uma comunidade humana que pretende o monopólio do uso legítimo da força física dentro de determinado território". ${ }^{7}$

Se não existissem instituições sociais que conhecessem o uso da violência, então o conceito de Estado seria eliminado, e surgiria uma situação que iríamos chamar de anarquia [...]. É claro que a força não é, certamente, o meio normal, nem o único do Estado - ninguém o afirma - mas um meio específico ao Estado. Hoje as relações entre Estado e a violência são especialmente íntimas.

Para que o Estado exista é necessário haver um conjunto de pessoas que reconheça a legitimidade de seu poder e obedeça a autoridade delegada aos detentores desse poder. A partir dessa constatação, Weber faz as seguintes perguntas: "Quando e por que os homens obedecem? Sobre que justificação íntima e sobre que meios exteriores repousa esse domínio?" 8

A partir desses questionamentos, Weber é levado a estudar os motivos pelos quais as sociedades consideram a autoridade do Estado como legítima. Para tanto, faz uma análise histórica por meio da qual desenvolve os tipos ideais de dominação: "tradicional", "carismática" e "legal".

Na dominação tradicional, a autoridade é exercida por patriarcas e a legitimidade de seu poder se dá em virtude do conformismo e da tradição; na dominação carismática, o poder é exercido por meio de lideranças que os homens obedecem não em virtude da tradição, mas porque acreditam nele. É representada por figuras como profeta ou, no campo da política, por algum líder que assume a forma de "demagogo".

Já na dominação legal, o domínio se dá em virtude da legalidade. É um tipo de dominação característico do Estado moderno em que a autoridade se impõe 6 FOUCAUT, Michel. Vigiar e Punir: Nascimento da prisão.

7 WEBER, Max. Ensaios de sociologia, 4a ed., Tradução: Waltensir Dutra. Rio de Janeiro: Zahar, 1979, p.98.

8 WEBER, Max. Ensaios de sociologia, p.99. 
em razão da crença na validade do estatuto legal e da competência funcional baseada nas regras racionalmente criadas. "É o domínio exercido pelo moderno 'servidor do Estado' e por todos os portadores do poder que, sob esse aspecto, a ele se assemelham".9

Segundo ele, a obediência, independente do tipo de dominação, é determinada pelo medo e pela esperança. Medo da vingança dos detentores do poder e esperança na recompensa que poderia se caracterizar por despojos, ou exploração de povos dominados, monopólio de cargos, recompensa material ou honraria pessoal. ${ }^{10}$

A partir desse estudo, Weber faz uma análise da racionalização das sociedades, mediante a qual se tornou conhecida como Sociologia do Conhecimento. Weber analisa o processo de racionalização da sociedade na passagem da Idade Média para a Idade Moderna e identifica que a mediação das relações sociais baseadas na tradição e no carisma dão lugar à racionalidade burocrática, característica das sociedades capitalistas.

Segundo o autor, "o Estado moderno é uma organização compulsória que organiza a dominação. Teve êxito ao buscar monopolizar o uso legítimo da força física como meio de domínio entre os territórios"11.

O tipo de dominação legal seria, portanto, fruto de um processo de racionalização e consequência lógica do progresso científico e do desenvolvimento do capitalismo, em que Estado assume uma autoridade isolada, controlando os meios de organização política. Tomando como ponto focal o tipo de dominação legal, ao fazer uma análise do estado comparada com um sistema organizacional, Weber cria algumas categorias teóricas que pela sua lucidez e originalidade conseguiram ultrapassar as fronteiras de seu tempo.

A principal categoria relaciona-se à administração burocrática. De acordo com Weber, a burocracia não é algo excluso das sociedades modernas, mas é precisamente nesse período que ela se desenvolve plenamente ${ }^{12}$.

9 WEBER, Max. Ensaios de sociologia, p.99.

10 WEBER, Max. Ensaios de sociologia, p.99-101.

11 WEBER, Max. Ensaios de sociologia, p.103.

12 WEBER, Max. Ensaios de sociologia, p.229. 
A burocracia moderna para o referido pensadorfunciona sob formas específicas. Compreende uma estrutura hierárquica formada por funcionários profissionais treinados e especializados para o exercício de suas funções. $O$ desempenho do cargo segue regras gerais mais ou menos estáveis que devem ser apreendidas. A burocracia rege o princípio de áreas de jurisdição fixas e oficiais, ordenadas por leis e normas administrativas. Ela é regulada por relações de autoridade delimitada por normas de competência colocadas à disposição dos funcionários ${ }^{13}$.

Constitui-se em um sistema formal em que a autoridade é legitimada por normas legais responsáveis por regular as relações e tornar o comportamento dos funcionários previsível e controlado.

A hierarquização das funções e a atribuição de responsabilidade aosfuncionários constituem-se em um sistema firmemente ordenado de mando e subordinação. Esse sistema, segundo Weber, oferece aos governados a possibilidade de recorrer a uma decisão de uma autoridade inferior para a autoridade superior, de uma forma regular e com precisão ${ }^{14}$.

Outra marca característica da burocracia é a impessoalidade, uma vez que não há vinculação das ações às pessoas, mas sim aos cargos. Os funcionários recebem compensações pecuniárias regulares, criando-se certa segurança social em troca das atividades exercidas por ele, diferindo, assim, do sistema tradicional baseado no patrimonialismo. Essa remuneração é definida pela tarefa realizada, por suas particularidades e pela posição hierárquica do cargo $^{15}$.

O Sistema de justiça estaria inserido dentro desse aparelho estatal burocrático, estruturado de forma hierárquica, cujas decisões deveriam ser pautadas pela racionalidade e pelo respeito à legalidade em nome da segurança jurídica, abandonando critérios substantivos baseados em razões pessoais. Nesse sentido Weber assinala que:

A igualdade perante a lei e a exigência de garantias legais contra a arbitrariedade requerem uma objetividade de administração formal e

13 WEBER, Max. Ensaios de sociologia, p.229-232.

14 WEBER, Max. Ensaios de sociologia, p.230.

15 WEBER, Max. Ensaios de sociologia, p. 237. 
racional, em oposição à discrição pessoalmente livre, que vem da graça do velho domínio patrimonial. Se, porém um ethos - para não falarmos em instintos - se apossa das massas sobre qualquer questão individual, ele postula a justiça substantiva orientada por algum exemplo e pessoas concretas; e esse ethos invariavelmente entrará em choque com o formalismo e a objetividade fria e condicionada a regras da administração. Por este motivo, o ethos deve rejeitar emocionalmente o que a razão exige ${ }^{16}$.

Ao relacionar a burocracia e o Direito, Weber faz comentários muito lúcidos sobre a justiça baseada em precedentes, característica de sistemas jurídicos de Common Law, afirmando que o modelo da Inglaterra dificilmente poderia ser aplicado a outros países da Europa por ser destituído de racionalidade e baseado na tradição. Para Weber, essa segurança jurídica era fundamental para o sistema capitalista e somente poderia ser garantida por meio do legalismo ${ }^{17}$.

A delimitação de competência hierárquica seria fundamental para assegurar essa segurança. Assim a ordem somente poderia ser considerada legítima se aplicada por um conjunto de pessoas autorizadas a fazer cumprir a ordem ou a castigar a violação. Essa seria uma das marcas características do Estado moderno, a racionalização do direito. Com a atribuição do monopólio da Justiça formal ao Estado, nega-se a legitimidade de todas as outras ordens judiciais informais não estatais.

\section{CRISE E DISFUNÇÃO DO PARADIGMA RETRIBUTIVO}

A estrita legalidade, tão cara às sociedades modernas, defendida no plano sociológico pelo modelo burocrático weberiano e no âmbito filosófico pelo positivismo jurídico, não foi capaz de impedir que a humanidade vivenciasse uma série de acontecimentos que colocaram em dúvida sua real capacidade de trazer as respostas diante da complexidade da relação entre sociedade e estado. Após a Segunda Guerra Mundial, surge um novo paradigma do constitucionalismo e com ele discussões relacionadas à abertura constitucional dos estados a uma série de princípios e valores fundamentados na dignidade da pessoa humana.

17 WEBER, Max. Ensaios de sociologia, p.252. 
Conforme Boaventura de Sousa Santos, o paradigma da modernidade deixa de poder renovar-se e entra em crise final dando sinais da emergência de um novo paradigma. A partir de então, começa-se a discutir sobre a necessidade de uma quebra de paradigma do Estado e com ele o seu modelo racional, formalista e burocrático. Essa crise ocorre no momento em que os mecanismos tradicionais de neutralização dos conflitos já não eram mais capazes de afastar as tensões, obrigando o aparelho estatal a ampliar o poder discricionário de seus organismos judiciais, legislativos e burocráticos para manter intocado seu padrão de dominação ${ }^{18}$.

Nesse sentido, Wolkmer ${ }^{19}$ assinala que:

[...] a crise que se abate sobre o arcabouço jurídico tradicional está perfeitamente em sintonia com o esgotamento e as mudanças que atravessam os modelos vigentes nas ciências humanas [...]. Daí a obrigatoriedade de se propor a discussão sobre a "crise dos paradigmas", delimitando o espaço de entendimento da crise na esfera específica do fenômeno jurídico. A crise, portanto, no âmbito do Direito.

Na convergência do pensamento crítico exposto é a manifestação de Warat, ${ }^{20}$ ao advertir que "[...]a procura da verdade nos termos que a ciência mecanicista é colocada, é por si mesma violenta. É uma forma de manipulação do mundo e dos outros". Seja a "verdade como correspondência fática e verdade como interpretação, ambas são manipuladoras". Justificável, assim, o desvelo teórico desse autor quando busca romper tais barreiras ao transitar por outros vieses com as suas severas críticas ao dogmatismo e à interpretação formalista da lei, ao defender em outras passagens sobre a necessidade de lentes transformadoras da vida por reconhecer que "Existe muita estupidez imobilizadora em nossa cultura de frases feitas, conceitos rotinizados e verdades fatigadas. Uma estupidez que todas as gerações herdaram." 21

18 SANTOS, Boaventura de Sousa. O Estado e o Direito na Transição Pós-Moderna, Revista Crítica de Ciências Sociais, n 30, p. 13-44 jun, 1990.

19 WOLKMER, Antônio Carlos. Crise da Justiça e democratização do Direito. 1 ed. Joaçaba: UNOESC, 1999, p. 69.

20 WARAT, Luis Alberto. O ofício do mediador. Florianópolis: Editora Habitus, 2001, p.19.

21 WARAT, Luis Alberto. O ofício do mediador. Florianópolis: Editora Habitus, 2001, p.24. 
Tais críticas cabem ao sistema penal vigente, direcionando-se ao paradigma retributivo adotado há séculos, pelo reconhecimento de que o uso e a finalidade das sanções em seus pressupostos já não se encontram em sintonia com os novos sentidos atribuídos à idéia de segurança pública, pois não reabilitam o infrator e, muito menos, consideram a vítima ${ }^{22}$.

A partir da obra "Estrutura das Evoluções Científicas" de Thomas Kuhn, Howard Zehr ${ }^{23}$ afirma que é possível haver uma revolução na forma como se vê o mundo a partir de uma substituição de modelos paradigmáticos. Ao mesmo tempo, o surgimento de novos paradigmas tem relação direta com a tentativa de resolver problemas prementes em uma sociedade. À medida em que vão surgindo fenômenos relacionados a problemas sociais e disfunções que deixam de coadunar com o paradigma e, não obstante as tentativas de superação das crises por meio de reformas para a manutenção do paradigma, este, com o tempo, tende a ser substituído.

Isso é percebido no âmbito do paradigma jurídico do estado punitivo. $O$ problema que o paradigma tentava resolver era a necessidade de o estado legitimar e consolidar o seu poder. Nas primeiras manifestações de justiça retributiva, as punições eram severas, inexistindo correlação entre a gravidade do delito e a pena imposta.

Com as transformações do Estado e das sociedades, o paradigma punitivo foi passando por transformações, cedendo espaço a novas possibilidades de modelo. Como detentor do monopólio do uso da força, o Estado implementou uma série de medidas para o controle social e resolução de conflitos de natureza penal. Superou-se a vingança privada, chegando à criação das prisões como uma estratégia de humanização das penas e superação dos castigos corporais e pena de morte. O encarceramento deveria, então, atender às necessidades sociais de punição e reeducação dos presos ${ }^{24}$.

22 SILVA, Maria Coeli Nobre da. Justiça de proximidade (Restorative Justice): Instrumento de proteção e defesa dos direitos humanos para a vítima. Curitiba: Juruá Editora, 2009.

23 ZEHR, Howard. Trocando as lentes: um novo foco sobre o crime e a Justiça. São Paulo: Palas AtChena, 2008, p. 86.

24 ZEHR, Howard. Trocando as lentes: um novo foco sobre o crime e a Justiça, p. 61. 
No século $X X$, o modelo de punição baseado no aprisionamento chegou a situações extremas, com enorme volume de pessoas privadas da liberdade, baixa eficácia na ressocialização e registros constantes de situações cruéis e de profunda violência dentro do sistema prisional. Assim, surgem gradualmente discussões sobre a utilização de alternativas ao encarceramento, representando um nova tentativa de "remendar o paradigma", mantendo-o "de pé"25. Afinal, sob o lúcido raciocínio de Warat, ${ }^{26}$ a realidade mostra que "Tudo está sendo criado a cada momento; a vida é um fluxo contínuo de criatividade. Toda existência está sempre nascendo".

Com efeito, tais alternativas assumiram formas variadas como prestação de serviços à comunidade, indenização e assistência às vítimas. Contudo, pelo fato de serem criadas como um "epiciclo" para ajustar o paradigma, acabam por não questionar o fundamento da punição, não representando nenhum impacto sobre os problemas do sistema penal, especialmente o atinente à superlotação carcerária ${ }^{27}$.

Diante da crítica a este ciclo de reformas, surgem as teorias abolicionistas como propostas voltadas para a superação do atual modelo, seja no sentido de exclusão total do sistema penal, seja no sentido de manutenção de um estado mínimo ${ }^{28}$. Independente da postura adotada, invariavelmente, a crítica abolicionista se dá com relação ao uso da punição pelo aparelho estatal, que não se configura como um meio adequado para se reagir diante de conflitos intitulados artificialmente de "delitos". Por meio de sua estrutura formal, burocrática, hierárquica e impessoal, o sistema acaba por perpetuar uma ordem social seletiva e injusta. Em que pese as discordâncias quanto aos limites da

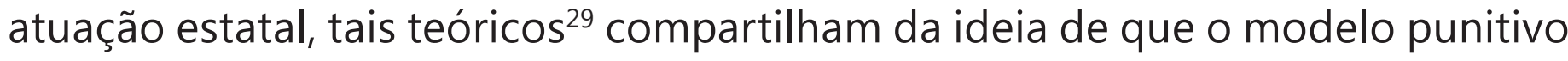
é estruturalmente incapaz de cumprir com a função de pacificador social, mostrando-se um instrumento de exclusão.

25 ZEHR, Howard. Trocando as lentes: um novo foco sobre o crime e a Justiça, p. 89.

26 WARAT, Luis Alberto. O ofício do mediador. Florianópolis: Editora Habitus, 2001, p.42

27 ZEHR, Howard. Trocando as lentes: um novo foco sobre o crime e a Justiça, p. 90.

28 MONTE, Mario Ferreira. Da realização Integral do Direito Penal. In: ARS IVDICANDI

- Estudos em Homenagem ao prof. Doutor Antônio Castanheira Neves. V. III, Coimbra: Coimbra Editora, 2008.

29 Nesse sentido Zerh, Howard. Trocando as lentes: um novo foco sobre o crime e a Justiça. 
Para esse contexto, precisa a observação via lentes transformadoras de Warat ${ }^{30}$ de que:

O homem determinado pelo grande paradigma da modernidade está passando pelos duros momentos de quebra total de sua visão de mundo. De repente, descobriu que seu olhar envelheceu e que agora começa a enxergar tudo fora de foco, que sua nitidez no olhar sumiu, e que precisa de óculos, apesar de não encontrar as lentes adequadas.

Dentro dessa perspectiva, começa-se a repensar sobre o monopólio estatal na esfera penal e sobre o surgimento de múltiplas portas não inseridas no aparelho do Estado para a solução dos conflitos. Como uma necessidade de superação da crise que se instaurou no sistema penal, surge a proposta da justiça restaurativa como novo paradigma de tratamento consensual para o conflito penal.

\section{A JUSTIÇA RESTAURATIVA COMO ALTERNATIVA AO SISTEMA RETIBUTIVO PUNITIVO}

A inquietude doutrinária diante do tradicional modelo epistemológico de ardorosa defesa de um sistema positivado, técnico e formal dos ordenamentos jurídicos, conduziu uma plêiade de estudiosos em áreas diversas - juristas, antropólogos, economistas, cientistas políticos e psicólogos - a se irmanarem em busca de outra referência capaz de fornecer resposta aos conflitos sociais por meio do primado da vontade consentida ao invés da orientação excessivamente positivista que impõe o predomínio da norma. Sabe-se ser algo usual ao Direito trabalhar com os conflitos, todavia, a solução destes por método não adversarial ainda se apresenta incomum na cultura jurídica, e só recentemente tem ocupado mais seriamente as reflexões dos pesquisadores brasileiros. A justiça restaurativa, por suas peculiaridades, surge, portanto, como uma alternativa para superação dos problemas apresentados pelo paradigma retributivo. E ao emergir absorveu os ares promissores de que "Particularmente, em relação ao Direito, há uma sabedoria que não aceita mais, como exclusiva, a razão normativa e começa

30 WARAT, Luis Alberto. O ofício do mediador. Florianópolis: Editora Habitus, 2001,p.70-71 
a pensar nos Direitos, em uma rede de múltiplas dimensões ocupadas com a qualidade de vida", como indicado por Warat ${ }^{31}$.

\section{Justiça Restaurativa - O sistema punitivo sob novas lentes}

Recepciona-se a Justiça Restaurativa como um sistema não coercivo, cujo escopo é restabelecer as relações destruídas pela emergência do conflito (não exclusivo da área penal/criminal), reconstruindo-as sob os parâmetros da voluntariedade e cultura não adversarial. Tal modelo insere vítima e ofensor em uma relação dialógica, mediante a qual se busca resgatar as relações rompidas por meio da construção de consenso em que as partes participam coletiva e ativamente na elaboração de soluções para a cura dos traumas e das perdas causados pelo crime.

Segundo Howard Zehris, um dos pioneiros na abordagem sobre o tema, o crime não se constitui apenas em um ato contra a sociedade corporificada na figura do Estado, mas sim uma violação que envolve as relações entre o infrator, a vítima e a comunidade. Assim, cumpre à Justiça identificar as necessidades e as obrigações oriundas dessa violação e do trauma causado e restaurar as relações.

O modelo restaurativo institucionaliza-se no cenário internacional entre os anos sessenta e setenta com o despertar dos interesses pelo movimento social emergente das formas alternativas de resolução de conflitos ${ }^{33}$, expressão atualmente substituída por formas adequadas de resolução de conflitos. O apelo ao retorno da autocomposição (de primitiva época) é feito quando os novos desafios postos ao Judiciário pelas intrincadas demandas da vida contemporânea não conseguem ser vencidas pela insuficiência dos mecanismos tradicionais.

31 WARAT, Luis Alberto. Surfando na pororoca. O ofício do mediador. Florianópolis: Boiteux, 2004, p.69

32 ZEHR, Howard. Trocando as lentes: um novo foco sobre o crime e a Justiça, p.174.

33 Essas modalidades ou formas foram difundidas, a princípio, pela sigla em inglês ADR ( Alternative Dispute Resolution), no espanhol RAD (Resolución Alternativa de Disputas), no francês MAC (Médition Arbitrage Conciliation), em Portugal RAL (Resolução Alternativas de Litígios) e/ou MARC (Métodos Alternativo de Resolução de Conflitos) ou MASC (Meios Alternativos de Solução dos Conflitos) como utilizadas no Brasil, expressão que atualmente firma-se na doutrina como Formas Adequadas de Resolução de Conflitos. 
Dentre as proposições do movimento aludido, identifica-se o modelo da Justiça Restaurativa - nominada na doutrina americana de Restorative Justice, e na França e Canadá como Justice de Proximité/Justice Réparatrice -, em sua acepção mais ampla, com contornos em todas as áreas conflituosas. Fruto de uma conjuntura complexa, com remotas práticas (o caso dos Maoris neozelandeses e aborígenes australianos) ${ }^{34}$, o novo modelo labora diretrizes para reduzir os papéis de atores do sistema judicial de uma justiça institucionalizada. Também se coloca em defesa de menos intervenções do sistema e se propõe a ser apta e eficaz para atender de forma mais aberta e satisfatória à solução do conflito, uma vez que realça responsabilizações.

A Justiça Restaurativa insere-se no espaço maior da reforma da administração da justiça em seu esforço de reconhecer os meios não judiciais de resolução de conflitos processados fora do direito estatal, cujas práticas permitem a intervenção construtiva da sociedade, como parte de um prospecto maior de intento à informalização e à desjudicialização ${ }^{35}$. Estas têm sua construção conceitual extraída de dentro do sistema judicial como resposta ao excesso de formalismo, aos elevados custos, ao difícil acesso à justiça e à morosidade em obter a prestação jurisdicional. Assim, a realidade confrontada e desafiada com a informalização e a desjudicialização mobiliza os atores sociais para formas mais simples de solucionar seus conflitos, contrapondo-se ao sistema judicial burocratizado e monopolizador tão próprio ao Estado weberiano.

Tal modelo contrasta com o modelo formal e profissionalizado que tem dominado a administração da justiça, ao oferecer processos, instâncias e instituições descentralizadas. Resgata experiências, via de regra, abundantes na sociedade, porém abandonadas e postas a desuso desde o monopólio estatal a retroalimentar-se da e na da teoria monista ou unitária do direito ${ }^{36}$.

34 SILVA, Maria Coeli Nobre da. Justiça de proximidade (Restorative Justice): Instrumento de proteção e defesa dos direitos humanos para a vítima, p. 138.

35 PEDROSO, João; TRINCÃO, Catarina; DIAS, João Paulo de. Percurso da Informalização e da desjudicialização por caminhos da reforma da administração da justiça:análise comparada. In: Observatório Permanente da Justiça Portuguesa. Centro de Estudos Socias. Faculdade de Economia. nov., 2001, p.29-32

36 WOLKMER, Antônio Carlos. (2001). Pluralismo Jurídico: fundamentos de uma nova cultura no Direito. 3. ed. São Paulo: Salfa Omega, p. 171-172. 
Como uma justiça de proximidade opera seu instrumental para firmar-se como um novo paradigma de justiça em sua proposta de dar condições ao corpo social de sentir uma "justiça com ele" ao invés de uma "injustiça sistêmica sobre ele"

Por meio de seu potencial de instrumentalidade e pela considerável diversidade de suas práticas, sob facho bifocado no conflito e nas repercussões na vida de todos os envolvidos, possibilita a perspectiva do justo processo construído, horizontalmente, com respeito às singularidades dos valores das pessoas implicadas. Baseado na ética do diálogo, da inclusão e da responsabilidade, o sistema objetiva a reparação/restauração do dano causado, e esta intencionalidade de assumir a obrigação reparadora conduz a Justiça Restaurativa ao alcance de suas metas, qual seja, a de gerenciar conflitos e tensões ao reparar danos e construir relacionamentos.

Visão que se encaixa à riqueza da sensibilidade de Luis Alberto Warat ${ }^{38}$ quando defende a 'mediação' como um dos programas adotados pela Justiça Restaurativa:

Esse programa não é uma técnica, nem uma filosofia ao modo tradicional, ele é uma forma de ver a vida que encontra o sentido da mesma, unicamente, vivendo-a. Falo da mediação como uma forma de cultura, um determinante de uma forma de vida.A mediação com sensibilidade introduz o amor como condição de vida, com uma forma de sentir e encontrar sentido para a vida[...]. Por intermédio da mediação com sensibilidade se tentaria reintroduzir no conflito o amor.

Para Warat, ${ }^{39}$ o "conflito somente será 'dissolvido' se houver uma intervenção sobre os sentimentos, uma preocupação com o valor sentido pelas pessoas". O que importa para elas, o que as faz sofrer ou ser feliz, isto é o que vai possibilitar e permitir uma solução adequada, encerra o autor:

O grande segredo, a meu ver, da mediação, como todo segredo, é muito simples, tão simples que passa despercebido. Não digo tentemos entendê-lo, pois não podemos entendê-lo. Muitas coisas em um conflito estão ocultas, mas podemos senti-las. Se tentarmos entendê-las, não encontraremos nada, corremos o risco de agravar o problema.

37 SILVA, Maria Coeli Nobre da. Justiça de proximidade (Restorative Justice): Instrumento de proteção e defesa dos direitos humanos para a vítima.

38 WARAT, Luis Alberto. O ofício do mediador. Florianópolis: Editora Habitus, 2001, p.41

39 WARAT, Luis Alberto. O ofício do mediador. Florianópolis: Editora Habitus,2001, p.57 
Com efeito, inserida no eixo de transformação do papel governamental e da comunidade, acarreta mudanças de várias ordens como na própria missão dos agentes governamentais, mudança do foco centrado na relação Estado/agressor para dar maior atenção à vítima e à comunidade, cuja realização pode submeterse à articulação das instituições estatais, como pode ser executado 'a latere'.

Desse modo, no plano teórico, o modelo restaurativo resgatado da exponencial doutrina carrega em si a confiança de solucionar as relações conflituosas de maneira pacífica e de modo negociado contando com comprometimento das partes envolvidas. No plano prático, tal modelo afirma-se como uma nova tendência sistêmica em que, diante do conflito, os próprios implicados conjuntamente buscam solucioná-lo da melhor maneira e de forma a alcançar as consequências e os desdobramentos futuros da ação ofensiva. Esta intervenção depende de um conjunto de fatores: a natureza da agressão; o dano social; o relacionamento entre os interessados primários e secundários; além de sujeitar-se às linhas mestras adotadas e consideradas em sua diversidade de métodos que possuem procedimentos flexíveis que se obriga a desenvolver para ajustar-se às partes.

Cumpre observar que a implementação de um modelo diferenciado nos espaços em que foi recepcionado (de predomínio na área penal) deveu-se de certa forma ao mecanismo denominado de diversificação, ${ }^{40}$ por meio do qual se abriram os canais permissivos de alternativas ao vigente modelo de enraizado perfil retributivo. É que um modelo restaurativo para se realizar exige outro padrão de ação, pede uma alternatividade que, ao ser adotada, produza mudanças na questão persecutória do sistema penal. De acordo com Francisco Amado Ferreira ${ }^{41}$, a diversificação surge como "sinônimo de desjudiciarização em sentido amplo" para abraçar tanto a "transferência de competências de resolução de litígios para instâncias não judiciais" como também para abranger "a não submissão para estas últimas de questões que se mantenham à sua margem"42.

40 Com equivalência conceitual com "desjudiciarização" em sentido amplo, a Diversão pode ser recepcionada como um desvio do caminho persecutório antes de chegar à solução jurídico-penal, a ter início com a retração policial, nos chamados delitos de bagatela, até os programas mais intensos que impedem o encarceramento. Pafa maiores informações: FERREIRA, Francisco Amado. Justiça Restaurativa. Natureza, Finalidades e Instrumentos. Coimbra: Coimbra Editora, 2006, p.28.

41 FERREIRA, Francisco Amado. Justiça Restaurativa. Natureza, Finalidades e Instrumentos, p.28

42 Exempificando com a realidade brasileira a presença da diversificação foi sentida no exsurgimento dos Juizados Especiais Cíveis e Criminais (assentidos pela Constituição Federal 
Como visto, a Justiça Restaurativa abebera na fresta aberta pela diversificação, e "aproveita a alteração verificada nas margens de tolerância em relação a comportamentos inseridos nas áreas de regulação social"43. Como indicativos desse aproveitamento, o modelo restaurativo principia-se com sua utilização direcionada a diversas situações de menor potencial ofensivo. Quer dizer, quando a defesa de certos bens não se manifestava tão importante ao interesse público, em circunstâncias conflituosas de pouca gravidade, quando era mínimo o abalo social decorrente da transgressão ou, ainda, quando em jogo relações afetivas cuja continuidade se pretenda preservar.

Todavia, no acompanhar de sua caminhada, verifica-se um modelo restaurativo com grau maior de abrangência, a ampliar sua utilização em áreas (antes não cogitadas), cujos bens defendidos são de grande interesse e de extrema importância para o interesse público, a exemplo dos conflitos ambientais e laborais. Para essa ampliação de horizontes, e sob a perspectiva do "aproveitamento" de que fala Francisco Amado Ferreira, a justiça restaurativa recebeu o calço da desconstrução do sistema anterior (o retributivo) para que pudesse emergir a partir de outros fundamentos filosóficos, "interfaceado a uma ética da singularidade, do pluralismo valorativo e interpretativo, a uma relação participativa atenta à justiça social", nas palavras de Eduardo Rezende Melo ${ }^{44}$.

Sabe-se ser a retribuição "uma das ideias-força de nossa civilização", pelos valores que em dada sociedade justificam o seu conteúdo, conforme expressa Giusepe Bettiol ${ }^{45}$. Do mesmo modo, é assente ser Kant o pensador referencial na discussão e na fundamentação do modelo retributivo, a influenciar até os dias atuais o pensamento sobre a pena, permanecendo o propósito retributivo como fundamento filosófico da grande maioria dos sistemas penais. Mas nas últimas

de 1998- art.98, inciso I) com as Leis 9.099/95 e 10.259/01, pelos institutos da 'transação', 'composição civil dos danos' e a 'suspensão condicional do processo' assunto melhor analisado e submetido a críticas em tópico próprio desenvolvido adiante

43 FERREIRA, Francisco Amado. Justiça Restaurativa. Natureza, Finalidades e Instrumentos, p. 28.

44 MELO, Eduardo Rezende. Justiça restaurativa e seus desafios histórico culturais. Um ensaio crítico sobre os fundamentos ético-filosóficos da justiça restaurativa em contraposição à justiça retributiva". In: SLAKMON Catherine et al. (Org). Justiça Restaurativa. Ministério da Justiça. Programa das Nações Unidas para o Desenvolvimento. Instituto de Direito Comparado e Internacional de Brasília - IDCB, 2005, p.53-78.

45 BETTIOL, Giusepe. Diritto penale. Padua: Cedan, Pádua, 1976, p. 691. 
décadas sedimenta-se a crítica a esse perfil retributivo, em que a reflexão do direito como ideia universal e abstrata, do direito pela coerção de Kant, tende a perder sua força. A conotação de um acerto de contas dosimétrico que sugere a regra ética, regra universal de liberdade que dá sentido à pena do sistema kantiano, se já não oferece expectativa para o ofensor, muito menos oferece perspectiva à pessoa ofendida, porque nem o sofrimento desta é amparado por inteiro e nem a experiência que viveu como ofendida pode ser apagada.

Para a alternatividade proposta, promovem-se mudanças por meio de uma releitura do Direito de fonte baseada em uma lei universal da liberdade segundo a qual "Conforme com o direito é uma ação que, ou cuja máxima, permite a liberdade do arbítrio de cada um coexistir com a liberdade de todos de acordo com uma lei universal" ${ }^{46}$. O suporte é encontrado na teoria crítica contemporânea, por meio da qual se pensa um Direito reinventado em bases articuladas com a ética e com a realização de uma justiça participativa e democrática.

Assim, em contraposição a um sistema formal de ética e de direito, como leciona Eduardo Resende Melo ${ }^{47}$, a ação não pode ser vista e tratada como se "estivesse isolada", mas, sim, "pensar a ação voltada às necessidades [...] deixá-la marcada pelos interesses e pelos conflitos de interesse, por sua singularidade em diálogo e oposição ao outro". A justiça restaurativa apresenta-se como alternativa diferenciada, pois se erige sobre os fundamentos filosóficos do "justo" construído pelas partes, em horizontalidade; do respeito às singularidades (valores) dos envolvidos na relação conflituosa; do olhar focado no conflito e suas repercussões, presentes e futuras, na vida do ofendido, ofensor e da comunidade; na prevalência da visão presente e prospectiva sobre a retrospectiva e na abertura do interpessoal para uma percepção social dos problemas em situações conflitivas.

Com efeito, submergindo-se nos escólios de Eduardo Rezende Melo ${ }^{48}$, significa apreender a justiça restaurativa por sua expressividade, ao pôr a vislumbre outra 46 COSTA, Alexandre Araújo. Cartografia dos métodos de composição de conflitos. in: GOMMA DE AZEVEDO, André (Org). Estudos em arbitragem, mediação negociação. BrasíliaGrupos de Pesquisa, 2008, p.161-201

47 MELO, Eduardo Rezende. Justiça restaurativa e seus desafios histórico culturais. Um ensaio crítico sobre os fundamentos ético-filosóficos da justiça restaurativa em contraposição à justiça retributiva". In: SLAKMON Catherine et al. (Org). Justiça Restaurativa, p.67

48 MELO, Eduardo Rezende. Justiça restaurativa e seus desafios histórico culturais. Um ensaio crítico sobre os fundamentos ético-filosóficos da justiça restaurativa em contraposição à justiça retributiva". In SLAKMON Catherine et al. (Org). Justiça Restaurativa, p.60. 
relação de poder entre indivíduo-sociedade com acertamento horizontal e pluralista, portanto diversa da usual visão vertical na definição do que é justo nos embates conflituosos. Ao centrar-se o novel modelo na singularidade valorativa das partes, permite ir ao âmago da relação e do que provocou o conflito, e dessa maneira ocorre o "rompimento da cisão entre interioridade e exterioridade que marca a concepção kantiana e que nos remete à possibilidade de emancipação".

Com a mira do olhar focada na relação conflituosa e não na "resposta estatal a uma regra abstrata prescritora da conduta" tida como transgredida, o "conflito e a tensão relacional ganha um outro estatuto". O pensamento não é mais aniquilar, rechaçar a ofensa pela punição, mas trabalhá-la de forma a extrair algo positivo de seu cometimento, para além de seus contornos destrutivos. Com tal proceder resolve-se não apenas o momento presente da relação conflituosa, mas a previne quanto ao futuro, o que poderia vir e/ou advir.

Ainda, por decorrência do respeito às singularidades dos valores, o sistema restaurativo de justiça "aponta para o rompimento dos limites colocados pelo direito liberal, abrindo-nos, para além do interpessoal, a uma percepção social dos problemas colocados nas situações conflitivas"49.

Segundo Boaventura de Sousa Santos ${ }^{50}$, o sistema restaurativo se reveste de características que revestem o modelo de considerável alcance no tocante aos resultados, como elencados: i) ênfase em resultados mutuamente acordados, em vez da estrita obediência normativa (consensualidade); ii) preferência por decisões obtidas por mediação ou conciliação, em vez de decisões obtidas por adjudicação (vencedor/vencido); iii) reconhecimento da competência das partes para proteger os seus próprios interesses e conduzir a sua própria defesa num contexto institucional desprofissionalizado e através de um processo conduzido em linguagem comum; iv) escolha como terceira parte de um não jurista (ainda

49 MELO, Eduardo Rezende. Justiça restaurativa e seus desafios histórico culturais. Um ensaio crítico sobre os fundamentos ético-filosóficos da justiça restaurativa em contraposição à justiça retributiva". In: SLAKMON, Catherine et al. (Org). Justiça Restaurativa, p. 60.

50 SANTOS, Boaventura de Sousa. O Direito e a comunidade: as transformações recentes da natureza do poder do Estado nos países capitalistas avançados. Revista Crítica de Ciências Sociais, n. 10, dez., p. 17, 1982. 
que com alguma experiência jurídica) eleito ou não pela comunidade; ou grupos cujos litígios se pretendem resolver; v) diminuto ou quase nulo o poder de coerção que a instituição pode mobilizar em seu próprio nome.

Na base da concepção da Justiça Restaurativa encontram-se ainda em alguns princípios que merecem destaque: voluntarismo, consensualidade, complementariedade, confidencialidade, celeridade economicidade, mediação e disciplina. Ovoluntarismo traduz-se na participação perfilada por uma vontadelivre de cooperar, de interiorizar responsabilidades por parte do ofensor, dos envolvidos se auto-comporem sem coerção. Para tanto, obrigatoriamente, devem as partes receber todos os esclarecimentos sobre seus direitos, a natureza do processo, as consequências da autocomposição e das geradas pelo descumprimento do acordado, cientes de estarem submetidas a um sistema diverso da tradicional atuação impositiva e unilateral própria do sistema judicial.

A consensualidade, por sua vez, significa a receptividade das partes à negociação, à aceitação livre e sem coerção dos pontos e premissas discutidos pelos implicados, de forma a conduzirem-se com concordância de opinião para solucionar o conflito da melhor maneira. Pela flexibilidade e pelo informalismo do processo restaurativo, este permite traçar planos para reconstruir as relações rompidas mesmo na visão do futuro, em um acordo que, segundo orienta Daniel Dana ${ }^{51}$, deve ser equilibrado, para conferir benefícios proporcionais às partes, com a clara e pormenorizada definição de quem fará o quê, quando, por quanto tempo, em que condições e com que garantias. Complementa-se com a redução por escrito de tudo que foi acordado e a renúncia a recursos, desde que cumprido devidamente o acordo.

O processo restaurativo impõe, ainda, o respeito à confidencialidade por parte de todos os intervenientes: seja quanto aos sentimentos expostos, seja quanto ao que foi espontaneamente confessado e/ou declarado. Ademais, é defeso a redução a escrito (com ressalva apenas do acordo final) e o uso de qualquer publicidade, e os trabalhos devem ser conduzidos à porta fechada, como importante para resguardar a dignidade das pessoas envolvida e atribuir maior credibilidade ao processo pela confiança instalada. 
Diversamente da morosidade do sistema de justiça tradicional, com prazos a serem cumpridos, fases recursais, ritos e formalidades, o processo restaurativo flexível, oral, simples em seus atos e formas tem sua duração controlada pelas próprias partes (auxiliadas por um 'tertius'), de acordo com as peculiaridades de casa situação. Ainda que não dispense as regras impostas pela mediação a se efetivar (mesmo que mais institucionalizada ou profissionalizada), a obtenção do acordo de maneira célere é de interesse dos envolvidos.

Ademais, os mecanismos utilizados pela Justiça Restaurativa, ainda que exijam recursos humanos interdisciplinares, têm custos materiais reduzidos e bem inferiores se levados em conta os parâmetros dos gastos despendidos com a estrutura da máquina oficial.

A administração e a gestão do instrumental restaurativo envolvem um processo negocial, sendo a "mediação" o mais presente, a se operar com a intervenção de um intermediário, chamado de mediador, indicado pelas partes ou integrado em serviço público em setores privados ou comunitários. A mediação compõe o processo restaurativo desde o seu início até a fase final, para oferecer a retaguarda à autocomposição decidida pelas partes, e se constitui, forma 'de autocomposição de interesses' e não de 'definição de direitos'52.

A justiça restaurativa requesta, portanto, obediência a medidas de ordem social acolhidas pelas partes envolvidas na ação ofensiva e danosa, um respeito obrigatório a todos, inclusive ao agente intermediador, até o integral cumprimento do acordo, a fim de manter sob credibilidade as atividades desenvolvidas na condução do processo restaurativo.

Todo o acervo da base doutrinária exposta reforça o entendimento de ter a Justiça Restaurativa o objetivo de construir compreensão, encorajar confiança e oferecer uma oportunidade de sarar e cuidar. Sem escamotear a face verdadeira do ato infracional tão comum nas defesas patrocinadas por profissionais nas lides do sistema tradicional (adversarial), a Justiça Restaurativa estimula o ofensor a responsabilizar-se pela ofensa causada de forma significativa para aperceber-se na relação causa e efeitos de seu comportamento ${ }^{53}$.

52 FERREIRA, Francisco Amado. Justiça Restaurativa. Natureza, Finalidades e Instrumentos, p.41.

53 No Brasil, o modelo de Justiça Restaurativa ainda se encontra carente de uma real difusão 


\section{Os Modelos Retributivo e Restaurativo em uma perspectiva comparada}

Para se ter a concepção clara sobre a Justiça Restaurativa, impende aferi-la diante dos parâmetros comparativos da justiça retributiva, modelo tradicional adotado pelas maiorias das culturas legais modernas, sustentada por um arcabouço complexo e de custoso aparato institucional. Neste arquétipo, como afirma Beristain" ${ }^{54}$, "O Estado, figura com o seu monopólio exclusivo, como a encarnação de uma divindade vingativa sempre pronta a retribuir o mal com outro mal", portanto a retribuição/ coação faz parte da essência do modelo tradicional retributivo, sedimentado sobre a ideia de culpa. Merece referência a lembrança de Luis Alberto Warat ${ }^{55}$, para quem "a lei no ocidente judaico-cristão, cumpre um papel totêmico, de superego da cultura, baseado no sentimento de moralidade culposa". Todavia, ainda que a natureza retributiva seja inerente ao sistema há séculos e culturalmente absorvida nas sociedades, a realidade mostra uma resposta deficitária desse modelo por ser incapaz de atender a muitos dos problemas postos a sua égide. Trata-se de um sistema repressivo, punitivo e de controle envolvido com ritos e cerimônias, protocolos simbólicos, intimidatórios e sobrevitimizantes, mas que não funciona para a responsabilização, não produz justiça, não satisfaz a vítima e nem repara o dano, como denunciam Mauro Cappelleti e Bryant Garth ${ }^{56}$.

Trazendo essa compreensão para relacioná-la ao tema sob análise, a Justiça Restaurativa revela-se em substancial dessemelhança com os parâmetros do modelo retributivo em praticamente todos os aspectos.

como política pública, haja vista que inexiste uma regulamentação apta a oferecer maior impulso e perenidade às experiências ocorridas em diversos estados. Apesar de constituir se constituir num modelo que prescinde da intervenção judicial ou estatal, mostra-se essencial a atuação oficial como elemento necessário para romper parte dos preconceitos dirigidos às práticas restaurativas e quebra com a tendência à reprodução acrítica das práticas tradicionais no campo da Justiça. Os primeiros projetos patrocinados pelo Ministério da Justiça e PNUD em 2005 deram origem a práticas pioneiras com a Justiça Restaurativa em Porto Alegre, São Caetano do Sul, Núcleo Bandeirante-Brasília/DF e, posteriormente, difundindo-se em outros Estados.

54 BERISTAIN IPINA, Antonio. Nova Criminologia à Luz do Direito Penal e da Vitimologia. Tradução de Cândido Furtado Maia Neto. Brasília:UNB, 2000, p. 54.

55 WARAT, Luis Alberto. O Monastério dos Sábios: o sentido comum teórico dos juristas. In: WARAT, Luis Alberto. Introdução geral ao Direito. vol. II. (A Epistemologia Jurídica da Modernidade). Porto Alegre: Sergio Antonio Fabris, 2002, p. 57.

56 CAPPELLETTI, Mauro; GARTH, Bryant. Acesso à Justiça. Tradução Ellen Gracie Northfleet. Porto Alegre: Sergio Antônio Fabris, 1988, p.08. 
Howard Zehr ${ }^{57}$, da cátedra de seus primeiros e pioneiros estudos sobre 0 movimento restaurativo, admitia uma espécie de cisão entre a justiça retributiva e a justiça restaurativa, como se não pudessem interatuar no funcionamento.

A Justiça Restaurativa comporta uma maneira diferente de refletir a transgressão e as suas respectivas consequências, e um de seus primeiros traços distintivos é o fato de a resposta à transgressão não vir do repertório de medidas punitivas que estão codificadas. Por reconhecer que o ato infracional ofende a vítima e a comunidade, e acarreta rompimento nas dimensões vítima/ delinquente/comunidade, a resposta deve embasar-se nas necessidades da vítima e da comunidade e não na necessidade de destacar a culpa do ofensor, sua periculosidade, seus antecedentes. Portanto, a ênfase está na situação fática: o dano causado, o trauma sofrido, o drama experimentado, assim os esforços devem ser empreendidos no sentido do prejuízo para reduzi-lo ao mínimo e restaurá-lo ao máximo.

De outra feita, uma segunda dissensão é identificada levando em conta que o modelo tradicional repousa no princípio da proporcionalidade da sanção segundo as características da infração (com especial atenção à sua gravidade) e as do infrator, enquanto o restaurativo tem por ditame o principio da responsabilidade. Na verdade, são as consequências vivenciadas e a capacidade de se negociar em cada caso concreto que auxiliam para que o resultado satisfatório seja obtido pelas partes envolvidas.

A terceira diferença delineia-se em relação ao princípio da mínima intervenção defendido pelo modelo restaurativo em detrimento da necessidade da intervenção repressiva do sistema retribucionista, de apego a fórmulas exclusivamente positivadas e a creditar sua operacionalidade ao formalismo do processo.

A quarta distinção apontada prende-se à questão da verdade perquirida no e pelo processo. Sabe-se que por meio de ritos solenes, inerentes à justiça tradicional, fixa-se o processo na investigação da verdade a emergir de um contexto probatório. Trata-se de uma verdade com caráter histórico, de mera

57 ZEHR, Howard. Trocando as lentes: um novo foco sobre o crime e a Justiça, p.259-261. 
reconstituição do que ocorreu, do ato transgressor já cometido por meio da prova coletada. Destarte, há uma íntima ligação entre a verdade e a prova, uma vez que a verdade tem que ser comprovada, porém essa inter/intra relação verdade e prova raramente proporcionam ao processo o real, "o verdadeiro", o conhecimento dos meandros da ocorrência transgressora, frustrando-se, desta maneira, a meta e objetivo a serem alcançados na processsualística desenvolvida. Como resultado, a "verdade" apresenta-se "estreita, parcial e restrita", simples verdade formal sobrepondo-se à verdade material. Com efeito, no sistema tradicional o "processo penal não existe para descobrir a verdade, e sim para determinar se é possível que o julgador obtenha um convencimento sobre a verdade da acusação, fundamentado em provas [... ${ }^{\prime 58}$.

Diversamente, a justiça restaurativa afasta-se de tal prática formalística, oferece como proposta a substituição da verdade material (raramente comprovada), pela verdade consensual, bem mais objetiva e sem se preocupar com as indagações de culpa. Tendo em vista o destaque que é dado ao consenso, cabe a quem for mais diretamente prejudicado pela infração (a vítima e/ou seus familiares) assumir uma participação central na solução do caso. Daí a aceitabilidade que deve ter essa verdade conceitual no desenvolver do processo, pelos sentimentos que envolvem, pelas consequências decorrentes, pela afetação às partes e à comunidade.

A quinta dissimilação identificada diz respeito ao princípio da igualdade. 0 sistema retributivo apresenta-se com uma gama de sanções codificadas, com a promessa de serem aplicadas de forma isonômica a determinadas circunstâncias delitivas, o que não acontece na realidade por uma série de razões, inclusive a de ordem econômica, o que faz da igualdade do sistema tradicional um mito, calcado no discurso mistificado do Direito Penal igualitário. A Justiça Restaurativa credencia-se bem mais propícia à efetivação dessa igualdade, conquanto atua com uma prática que valoriza o consenso, a concordância, a participação voluntária das partes envolvidas $A$ ausência de normas sancionadoras codificadas não significa processos desiguais. Já o modelo retributivista, apesar da prévia tipologia

58 PAZ, Silvana Sandra; PAZ, Silvina Marcela. Justiça Restaurativa - Processos Possíveis. In: SLAKMON Catherine et al. Justiça Restaurativa. Ministério da Justiça. Programa das Nações Unidas para o Desenvolvimento. Instituto de Direito Comparado e Internacional de Brasília - IDCB, 2005. pp.129-132 
punitiva, não garante condenação igual e justa, a prática demonstrando que se trata muito mais de uma igualdade dissimulada, em que na grande maioria dos casos ocorre a "invenção de condutas desviadas" 59 .

A imersão em seara comparativa dos dois sistemas revela um modelo retributivo fundado na regra racional, em que o poder se expressa na relação indivíduo/ sociedade, exercido de modo hierarquizado e vertical. É o Estado que, diante da ocorrência da violação, determina como resposta a regra aplicável ao caso. Já o modelo restaurativo "dá vazão a um acertamento horizontal e pluralista daquilo que pode ser considerado justo pelos envolvidos numa situação conflitiva", portanto são as partes na relação conflituosa que respondem à violação ${ }^{60}$.

Para o modelo retributivo, é desse poder estatal que emanam as regras valorativas, sem que se lhes possa opor ou questionar suas origens, postura própria de um monismo valorativo da estruturação da vida em sociedade que tem o Estado como única fonte de emanação do direito. No modelo restaurativo, a sustentação dos valores deve emergir da comunidade. O valor do justo e da justiça manifestam-se da relação entre as pessoas, e estas, em caso de conflito, não devem ser subtraídas de sua efetiva autonomia para resolver a situação conflituosa. Dessa maneira, abrem ensanchas "à construção de um outro modo de subjetivação não apenas da postura que se há de ter face ao conflito, como ainda, uma diversa percepção do outro com quem se confrontou e sobretudo da relação com a norma"61.

Ademais, o modelo retributivo fundamenta-se na lógica dedutiva, vem de cima, passando da regra de conduta à punição; enquanto no modelo restaurativo a lógica é indutiva, vem de baixo, por meio dos sentimentos vivenciados e interagidos. Assim, não é a regra que importa, mas "o processo de interpretação, de construção e de expressão destas regras".

59 PAZ, Silvana Sandra; PAZ, Silvina Marcela. Justiça Restaurativa - Processos Possíveis. In: SLAKMON Catherine et al. Justiça Restaurativa, p.129.

60 MELO, Eduardo Rezende. Justiça restaurativa e seus desafios histórico culturais. Um ensaio crítico sobre os fundamentos ético-filosóficos da justiça restaurativa em contraposição à justiça retributiva". In: SLAKMON Catherine et al. (Org). Justiça Restaurativa, p.60.

61 MELO, Eduardo Rezende. Justiça restaurativa e seus desafios histórico culturais. Um ensaio crítico sobre os fundamentos ético-filosóficos da justiça restaurativa em contraposição à justiça retributiva". In: SLAKMON Catherine et al. (Org). Justiça Restaurativa, p.60. 
Vinculado a pensamentos sistemáticos, de obediência irrestrita à norma e sem se preocupar em interagir com a comunidade, a concepção retributiva de justiça apela a uma incondicionalidade de valores universais que, no mais das vezes, nada dizem e nada representam para os envolvidos nos processos judiciais. As práticas restaurativas inovam, assim, ao introduzir na relação conflituosa a condicionalidade das regras sem dispensar o envolvimento comunitário, o que permite se pautar em sua conduta pela ética da reflexão da própria moral ante outras morais, dando azo a um chamamento de responsabilidade individual.

\section{CONSIDERAÇÕES FINAIS}

Com base no modelo tradicional delineado no estado burocrático weberiano, o sistema de justiça estrutura-se de maneira hierárquica e formal, em que existe uma intermediação de um aparelho integrante do Estado. O conflito é processado em moldes adversariais, fomentados os valores do individualismo e da competição, enfatizadas as diferenças, em que um dano social é cumulado a outros, e no qual os elementos-chave são o Estado e o ofensor. Por este modelo retributivo, há um distanciamento do indivíduo e, ancorado pelo dogma da impessoalidade, tornase indiferente quanto às necessidades do infrator, da vítima e das comunidades afetadas, a constituir-se, portanto, como um sistema excludente. Tal modelo, diante de todas as transformações sentidas pela sociedade, tem se mostrado ineficaz e incapaz de dar as respostas necessárias para a grande diversidade de situações de conflito com a lei, em especial nos casos envolvendo adolescentes.

De modo diverso e peculiar é o olhar sob a lente restaurativa, ao ter como central a solução do problema e o foco no futuro. Prima-se pelo diálogo, a busca de traços comuns, a reparação e a restauração, com ênfase para a reparação de danos sociais. O dano praticado é contrabalançado pelo bem realizado em proveito e atendimento das necessidades dos afetados, em especial das vítimas. Na relação social rompida o senso de equilíbrio é conseguido pela restituição.

A justiça restaurativa é focada em alguns princípios e valores que fazem dela um modelo distinto da justiça retributiva. Nela, investe-se nas relações sociais, 
impondo-se ao sujeito infrator o compromisso de recompor prejuízos, e de assumir a responsabilidade por reparar o dano, cabendo à comunidade contribuir para que as partes envolvidas restabeleçam a relação rompida. Enxerga-se, portanto, o crime como um ato que envolve não somente o Estado, mas também a vítima, e permite um tratamento de proximidade, primando pelo interesse das pessoas envolvidas na comunidade.

Por conseguinte, a Justiça restaurativa amplia a visão da resolução do conflito para além do Estado, legitimando a participação do ofensor, da vítima e da comunidade quando possível, por meio do diálogo da inclusão e da responsabilidade social, representando, indubitavelmente, uma importante mudança de paradigma no processo penal, com benefícios para o infrator e para a coletividade.

Ao valorizar o diálogo e a compreensão das diferenças, compromete-se com a inclusão e justiça social, sendo, portanto, condizente com o primado da dignidade e da promoção da democracia participativa. Diante desse quadro, a partir da substituição do paradigma tradicional, propõe-se a adoção da justiça restaurativa como um modelo alternativo para superar os problemas que o atual sistema de justiça não consegue enfrentar.

\section{REFERÊNCIAS DAS FONTES CITADAS}

BERISTAIN IPINA, Antônio. Nova Criminologia à Luz do Direito Penal e da Vitimologia. Tradução de Cândido Furtado Maia Neto. Brasília: UNB, 2000.

BETTIOL, Giusepe. Diritto penale. Padua: Cedan, Pádua, 1976.

CAPPELLETTI, Mauro; GARTH, Bryant. Acesso à Justiça. Tradução Ellen Gracie Northfleet. Porto Alegre: Sergio Antônio Fabris, 1988.

COSTA, Alexandre Araújo. Cartografia dos métodos de composição de conflitos. In: GOMMA DE AZEVEDO, André (Org.). Estudos em arbitragem, mediação negociação. Brasília-Grupos de Pesquisa, 2008, p.161-201.

DANA, Daniel. Adiós a los conflicto. Madrid: McGraw-Hill, 2001. 
ELIAS, Norbert. O processo civilizador:Uma história dos costumes. Tradução de Rui Jungmann. Rio de Janeiro: Jorge Zahar, 1994.

FERREIRA, Francisco Amado. Justiça Restaurativa. Natureza, Finalidades e Instrumentos. Coimbra: Coimbra Editora, 2006

FOUCAUT, Michel. Vigiar e Punir: Nascimento da prisão. Tradução de Raquel Ramalhete, Petrópolis: Vozes, 1999.

KANT, Immanuel. Metafísica dos costumes. Princípios metafísicos da doutrina.Parte 1. Tradução de Paulo Quintela, Lisboa: Ed. 70, 2004.

MELO, Eduardo Rezende. Justiça restaurativa e seus desafios histórico culturais. Um ensaio crítico sobre os fundamentos ético-filosóficos da justiça restaurativa em contraposição à justiça retributiva". In: SLAKMON Catherine et al. Org). Justiça Restaurativa. Ministério da Justiça. Programa das Nações Unidas para o Desenvolvimento. Instituto de Direito Comparado e Internacional de Brasília - IDCB, 2005, p.53-78.

MONTE, Mario Ferreira. Da realização Integral do Direito Penal. In: ARS IVDICANDI - Estudos em Homenagem ao prof. Doutor Antônio Castanheira Neves. V. III, Coimbra: Coimbra Editora, 2008.

PAZ, Silvana Sandra; PAZ, Silvina Marcela. Justiça Restaurativa - Processos Possíveis In: SLAKMON Catherine et al. Justiça Restaurativa. Ministério da Justiça. Programa das Nações Unidas para o Desenvolvimento. Instituto de Direito Comparado e Internacional de Brasília - IDCB, 2005, pp.129-132.

PEDROSO, João et al. Percurso da Informalização e da desjudicialização por caminhos da reforma da administração da justiça: análise comparada. Observatório Permanente da Justiça Portuguesa. Centro de Estudos Socias. Faculdade de Economia, 2001.

PINTO, Renato Sócrates Gomes. Justiça Restaurativa é Possível no Brasil? In: SLAKMON Catherine et al. Justiça Restaurativa. Ministério da Justiça. Programa das Nações Unidas para o Desenvolvimento. Instituto de Direito Comparado e Internacional de Brasília - IDCB, 2005, pp.129-132.

SANTOS, Boaventura de Sousa. O Estado e o Direito na Transição Pós Moderna. Revista Crítica de Ciências Sociais, n 30, jun., p. 13-44, 1990. Disponível: http://www. boaventuradesousasantos.pt/media/pdfs/Estado_Direito_Transicao_Pos-Moderna_RCCS30. PDF. Acesso em: 01 de dez., 2014. 
SANTOS, Boaventura de Sousa. O discurso e o poder: ensaio sobre a sociologia da retórica jurídica. Porto Alegre: Fabris, 1988.

SANTOS, Boaventura de Sousa. O Direito e a comunidade: as transformações recentes da natureza do poder do Estado nos países capitalistas avançados. Revista Crítica de Ciências Sociais, n. 10, dez., p. 09-40, 1982.

SCURO NETO, Pedro. Manual de Sociologia Geral e Jurídica. 5 ed. São Paulo: Saraiva, 2004.

SILVA, Maria Coeli Nobre da. Justiça de proximidade (Restorative Justice): Instrumento de proteção e defesa dos direitos humanos para a vítima. Curitiba: Juruá Editora, 2009.

WARAT, Luis Alberto. O ofício do mediador. Florianópolis: Editora Habitus, 2001.

WARAT, Luis Alberto. O Monastério dos Sábios: o sentido comum teórico dos juristas. In: WARAT, Luis Alberto. Introdução geral ao Direito. vol. II. (A Epistemologia Jurídica da Modernidade). Porto Alegre: Sergio Antonio Fabris, 2002.p.57-99.

WARAT, Luis Alberto. Surfando na pororoca: O ofício do mediador. Florianópolis: Boiteux, 2004.

WEBER, Max. Ensaios de sociologia. 4. ed. Tadução Waltensir Dutra. Rio de Janeiro: Zahar, 1979.

WOLKMER, Antônio Carlos. Crise da Justiça e democratização do Direito. Joaçaba: UNOESC, 1999.

WOLKMER, Antônio Carlos. Pluralismo Jurídico: fundamentos de uma nova cultura no Direito. 3. ed. São Paulo: Salfa Omega, 2001.

ZEHR, Howard. Trocando as lentes: um novo foco sobre o crime e a Justiça. São Paulo: Palas Athena, 2008.

Recebido em: fev/2016

Aprovado em: jul/2016 